\title{
Pseudoglandular Carcinoma of the Penis
}

National Cancer Institute

\section{Source}

National Cancer Institute. Pseudoglandular Carcinoma of the Penis. NCI Thesaurus. Code C159246.

A penile squamous cell carcinoma characterized by the formation of gland-like structures. 